\title{
Ripeness stage effects on quality characteristics of smoothies made up of sweet cherries (P. AviumL., cv. 'Lapins')
}

\author{
Teresa De Pilli and Giuseppe Lopriore* \\ Department of Science of Agriculture of Food of Environment, University of Foggia, 25 Via Napoli, 71100 Foggia, Italy
}

\section{A B S T R A C T}

\begin{abstract}
Sweet cherries are reported to contain substantial amounts of important phytochemicals such as anthocyanins and polyphenolics. Minimally processed fruits, like smoothies, retain a large quantity of phytochemicals and they could actually be considered a valid alternative to fresh eaten fruits. The effects of ripeness stage on quality and functional characteristics of smoothies of sweet cherries $(P$. avium L.) of a very important cultivar at international level (cv 'Lapins') and pasteurized by microwaves were studied. A significant decrease of $L *$ (from 25.96 to 23.33) and hue angle values (from 41.22 to 33.32) with ripeness stages was observed. The polyphenol content of smoothies increased significantly in successive ripeness stage (from 375.39 to $541.07 \mathrm{mg}$ gallic acid per $\mathrm{kg}^{-1}$ ) as the antioxidant capacity (from 11142.00 to $12412.67 \mu$ mol TEAC per $\mathrm{kg}^{-1}$ ). Also, the sensorial analysis results showed that the overall acceptability score increased from the first to third ripeness stages (from 4.20 to 8.30 ). This research highlights the importance of ripeness stage also for processed fruit. In particular, in our case, the production of smoothies by 'Lapins' sweet cherries should be carried out with fruits of the late harvest period in order to maximise functional and sensorial properties of this product.
\end{abstract}

Keywords: Smoothie; Sweet cherry; Ripeness stage; Prunus avium; Lapins; Microwave pasteurization.

\section{INTRODUCTION}

Fruits are rich sources of phytochemicals, such as carotenoids and polyphenolics, which include anthocyanin pigments, flavan-3-ols, procyanidins, flavonol glycosides, phenolic acids, and ellagic-acid derivatives (Ames et al., 1993; Aviram and Fuhrman, 2002; Bors and Michel, 2002; Oz and Kafkas, 2017), very useful for human health and well-accepted by consumers through all the year. In particular, sweet cherries are reported to contain substantial amounts of important phytochemicals such as anthocyanins and polyphenolics (Gao and Mazza, 1995; Wang et al., 1997; Viljevac et al., 2012; Wang et al., 1999a; Ferretti et al., 2010). This could be related with some beneficial effects of cherry consumption reported in the literature like alleviate arthritis and gout-related pain (Wang et al., 1999b; Seeram et al., 2002; Schumacher et al., 2013).

Minimally processed fruits, like smoothies, retain a large quantity of phytochemicals and they could actually be considered a valid alternative to fresh eaten fruits. Smoothies are thick in consistency and are normally consumed fresh or preserved for short periods (1-3 weeks) by storing in the refrigerator after pasteurisation or freezing. Generally, packaged smoothies are stabilized by conventional pasteurization treatment. Nevertheless, some researches on innovative stabilization processing were carried out. For example, there are only few literatures available related to microwave pasteurization of fruits puree during smoothies processing, which could reduce treatment time and save energy production costs. Moreover, an evaluation of qualitative characteristics of product submitted to this alternative treatment should be investigated.

Smoothies are among the fastest-growing segments in the beverages market, currently. They constitute the top of the line premium product range in NCSD (Non-Carbonated Soft Drinks) division. The smoothie market segment is flourishing in the developed, as well as, emerging markets.

\footnotetext{
${ }^{*}$ Corresponding author:

Giuseppe Lopriore, Department of Science of Agriculture of Food of Environment, University of Foggia, 25 Via Napoli, 71100 Foggia, Italy,

Tel:+39 (0)881 589310, E-mail: giuseppe.lopriore@unifg.it
}

Received: 20 May 2018; $\quad$ Accepted: 18 October 2018 
In recent years, fruit-based smoothies have gained a phenomenal popularity across North America, with the USA being the biggest market generating over USD 2 billion in a year and the smoothie production shot up by $120 \%$ from 2010-2015 in North America (Mordor Intelligence Analysts, 2017). Packaged smoothie are available based on one or more different type of flesh fruits, most frequently banana, apple, pear, peach, apricot, plum, strawberry, grapes, blueberry, raspberry and pineapple. While sweet cherries are between the less represented fruit and vegetable utilized by the smoothie industry. This is particularly noticeable in the smoothie Italian market. The worldwide cherry market for fresh consumption is experiencing, year by year, a considerable increase due to growing demand coming from emerging countries (Cappelletti et al., 2015). This can leads to maintain a quite high price of fresh sweet cherries, so lowering the interest of the food processing industry for this fruit. Despite this consideration, should be regarded the not negligible quantities of double cherries or spurs (where one side of the cherry is aborted), of cherries affected by light-medium cracking without rot or mildew development, of cherries defecting in size, shape and colour that are usually discarded, sometimes leaving them in the field, without any profitable destination. Moreover, it could be taken in consideration the very high average price of retail per litre of smoothies, made with different kind of fruits that recent years in Italy was about 6.50 euros for fresh smoothies and more than 5.00 euros in the case of UHT smoothies (Lonza, 2013).

The low diffusion of cherry-based smoothies and especially of scientific literature about them, offers no reference about their achievement and evaluation. Cultivar survey, and in particular ripeness stage, represents an important step when developing a new product (Cabezas-Serrano et al., 2009a; Cabezas-Serrano et al., 2009b) allowing identification of genotypes that better respond to minimal processing and storage of the product.

'Lapins' is a well-known sweet cherry cultivar widely represented in many of the major cherry producing countries like Canada, USA, Argentina, Chile, Italy, Spain, Germany, Turkey and Iran. 'Lapins' cultivar is a very productive, self-fertile and of commercial interest because of the large size, high firmness and resistance to rain cracking of its fruits, with only susceptibility to wind marking, that have mahogany to dark external colour, with flesh red when ripe, and matures 7 to 15 days later than Bing (Çalhan et al., 2014), but problems associated with maturity (pitting, stem, condition, size, flavour) of this cultivar also have been reported by Drake and Elfving (2002). To meet market and labour demands, 'Lapins' cherries are often picked before they have attained full flavour and proper maturity. Quality problems associated with maturity can be readily visible to the consumer, reducing market appeal of this fruit. For this reason seems to interesting to evaluate the possibility to devote 'Lapins' fruits to food industry in order to produce smoothie cherries. Moreover, to study all elements that could influence the quality, nutritional and functional characteristics of end product should be very important to study the ripeness effects on these characteristics. In fact, fruit compositions deeply change depending on its ripening stage (Serrano et al., 2005, Díaz-Mula et el., 2009). For these reasons, this research was carried out to evaluate the effects of ripeness stage on quality and functional characteristics of smoothies made up of sweet cherries (P. avium, cv. 'Lapins') and blanched and pasteurized by microwaves.

\section{MATERIALS AND METHODS}

\section{Raw materials}

Sweet cherries cv. 'Lapins', supplied by Netti Lucia's farm (countryside Sammichele, Bari, Italy) were used. Samples have been picked from a unique tree 19 years old having a crop load of almost $40 \mathrm{~kg}$, considering harvesting time referred to the date of optimal commercial harvest for fresh consumption. The three ripeness stages compared were obtained collecting the cherries at three successive harvest date that were: LI) 5 days before optimal commercial harvest, LII) at optimal commercial harvest, LIII) 5 days after optimal commercial harvest. On each harvest date an approximately $2 \mathrm{~kg}$ sample of fruit was collected randomly from around the perimeter of the tree 1 to $3 \mathrm{~m}$ above the ground. After each harvest, three sub-sample of 25 fruits each one were randomly extract from the original sample and they were immediately evaluated for weight, fruit colour, longitudinal diameter, transverse major and minor diameters, firmness. Then, some half pulps from depitted fruits of each sub-sample were used to evaluate total polyphenols content and antioxidant potential. The remaining part of each sub-sample was squeezed inside a plastic bag and the juice obtained used in the evaluation of $\mathrm{pH}$, titratable acidity (TA) and total soluble solids (TSS). The other part of the sample, about $1.5 \mathrm{~kg}$ of cherries, was used in smoothie preparation as described in the following paragraph. Physical parameters on the fruits have been evaluated as follows. The fruit removal force was determined measuring the torque needed to detach the drupe from the peduncle using a mechanical dynamometer mod. DM20 (Somfy Tec, France) modified welding a small fork on the terminal part of the instrument that hold the fruit at the junction between fruit and peduncle. Weight of single fruits was measured, after destemming, using a common laboratory technical scale. Fruit colour were evaluated with a colorimeter Minolta CR300 (Osaka, Japan) using the Hunter L*, a*, b* system and calculated 
the hue angle and the Chroma (McGuire, 1992). For each ripeness stage one hundred and fifty measurements were conducted. Each cherry of three repetition of 25 fruits were measured of both sides. Diameters were measured using a common digital caliper. Firmness was evaluated using a bench digital penetrometer Turoni (Forlì, Italy). Methods of determination of chemical parameters on cherries and cherry smoothies will be described together subsequently in the 'Analyses' paragraphs.

\section{Smoothie preparation}

Stem was removed from sweet cherries and, after washing, they were blanched by microwaves oven Samsung mod. CE 116KT (Seoul, South Korea) at 720 Watt for 330 seconds. The blanching treatments were carried out dipping 500 grams of cherries into 1 litre of distilled water. After, the sweet cherries were cooled by running water, stoned and grounded by cutting mill mod. GM 200 Grindonmix Retsch (Haan, Germany) at 10000 rpm for 30 seconds.

The obtained smoothie was putted into glass jar with capacity of $200 \mathrm{~mL}$ and sterilized by microwaves oven Samsung mod. CE 116KT (Seoul, South Korea) at 720 Watt for seven minutes. The maximum temperature reached during thermal treatment was $127^{\circ} \mathrm{C}$. This parameter was measured by graduated stripes of paper (VWR International mod. MELB1762/MELB1763, Milan, Italy) sensitive to heat put into smoothie during pasteurization. The treatments were carried out putting four open glass jar filled with smoothie into 1 litre of distilled water. After pasteurization, samples were hermetically closed and upside down for 20 minutes in order to favour the screw cap pasteurization. Subsequently, samples were cooled by running water for 20 minutes.

\section{Analyses}

Physical, chemical, and physical-chemical characteristics were evaluated both on fresh sweet cherries and smoothie samples. The following analyses were carried out: $\mathrm{pH}$ and titratable acidity, soluble solids, colour ( $\mathrm{L}^{*}$, hue angle, Chroma), polyphenol and antioxidant activities. Moreover, the sensory analysis was carried out on cherry smoothies. All analyses were replicate at least three times.

\section{$p H$ and titratable acidity (TA)}

The $\mathrm{pH}$ and the titratable acidity were measured using a pH meter Crison (mod. Meter_Basic 20, Spain) at $25^{\circ} \mathrm{C}$. For the $\mathrm{pH}$, the electrode was submerged directly in cherry juice or in the smoothie. For the titratable acidity, $40 \mathrm{~mL}$ of distilled water were added to $10 \mathrm{~mL}$ of fresh juice or smoothie samples in the ratio of $1: 4 \mathrm{v} / \mathrm{v}$, homogenised for 1 min, and then titrated with $\mathrm{NaOH} 1 \mathrm{M}$ until $\mathrm{pH}$ of 8.3; the volume of solution needed were recorded and converted to $g \mathrm{~L}^{-1}$ of citric acid.

\section{Total soluble solids (TSS)}

Fresh juice and smoothie samples were analysed through a digital refractometer DBA 35 (Giogio Bormac s.r.l., Carpi (MO), Italy). All tests were carried out at room temperature $\left(25^{\circ} \mathrm{C}\right)$.

\section{Colour measurement}

The colour of fresh fruits and smoothie samples was evaluated by a tristimulus colorimeter (Chromameter-2 Reflectance, Minolta, Osaka, Japan) equipped with a CR 300 measuring head.

Colour was expressed as $\mathrm{L}^{*}, \mathrm{a}^{*}$ and $\mathrm{b}^{*}$ calibrated to a standard white tile $\left(\mathrm{L}^{*}=91.7, \mathrm{a}^{*}=-1.16, \mathrm{~b}^{*}=1.06\right) . \mathrm{L}^{*}$ corresponds to lightness, $a^{*}$ represents red $(+) /$ green $(-)$ and $\mathrm{b}^{*}$ refers to yellow $(+) /$ blue $(-)$. Chroma and Hue angle were suggested to be more practical measures of colour (McGuire, 1992). Hue angle (h) was calculated from $\mathrm{h}=\arctan \mathrm{b} * / \mathrm{a}^{*}$ and Chroma was determined as $\left[\left(\mathrm{a}^{*}\right)^{2}+\right.$ $\left.\left(b^{*}\right)^{2}\right]^{0.5}$.

\section{Total polyphenols (TP)}

Phenolic extraction in fresh and processed sweet cherries was performed by addition of $5 \mathrm{~g}$ of fruit to $25 \mathrm{~mL}$ of water: methanol (2:8) containing $0.6 \mathrm{mg} \mathrm{NaF}$ (to inactivate polyphenol oxidase activity and prevent phenolic degradation), followed by homogenization for $1 \mathrm{~min}$, and then centrifugation at $5^{\circ} \mathrm{C}$ and $12,000 \mathrm{~g}$ for $10 \mathrm{~min}$.

The pellet was discarded and the supernatant was retained and used as extract. Total phenolics were determined according to the method of Singleton and Rossi (1965). Each extract $(100 \mu \mathrm{L})$ was mixed with $1.58 \mathrm{~mL}$ water, $100 \mu \mathrm{L}$ of Folin-Ciocalteau's reagent and $300 \mu \mathrm{L}$ of sodium carbonate solution $\left(200 \mathrm{~g} \mathrm{~L}^{-1}\right)$. After $2 \mathrm{~h}$ standing, the absorbance was read at $725 \mathrm{~nm}$ against a blank, with a spectrophotometer UV/Vis (PerkinElmer, mod. Lambda 25 , Milan, Italy). The total phenol content was calculated based on the calibration curves of gallic acid, and expressed as $\mathrm{mg}$ of gallic acid equivalents per $1 \mathrm{~kg}$ of fresh weight.

\section{Determination of antioxidant capacity}

Antioxidant capacity was determined by scavenging of the radical 2,2-diphenyl-1-picrylhydrazyl (DPPH) as described by Melichácová et al. (2010).

\section{Sensory Analysis}

Quantitative Descriptive Analysis (QDA) was used to perform the sensory analysis of the sweet cherries smoothies using a descriptive scaling and presented with a spider web following Santana et al. (2015). Out of 30 potential panellists, consisting of employees of University of Foggia, the ten panellists were selected through prescreening questionnaires, duo-trio tests, ranking screening 
tests carried out on commercial smoothies as a function of flavour, taste and texture attributes (Meilgaard et al., 1999). Sensory evaluation was conducted in duplicate for each sample.

\section{Statistical analysis}

The variance analysis (ANOVA) was carried out on results obtained from analytical indexes by software StatSoft ver. 6.0 (Statsoft, Tulsa, USA). The means of these results were compared by the Fisher's test.

\section{RESULTS AND DISCUSSION}

It is widely accepted that the main characteristics related to sweet cherry quality are fruit weight, colour, firmness, sweetness and flavour. Table 1 reports physical and chemical parameters of fresh sweet cherries harvested at three different ripeness stages. It shows that there are significant differences among ripeness stages in luminosity $\left(L^{*}\right)$, hue angle, Chroma and firmness of fresh fruits. In particular, $\mathrm{L}^{*}$ and Chroma values decreased only between the first and second ripeness stage (LI and LII), while hue angle and firmness show quite huge differences during ripeness stage investigated. Both parameters declined from LI to LIII, that means the skin colour progressively changed from red to dark-red, and lowering of the fruit firmness denote softening of the skin texture.

In sweet cherry, the ripening is characterized by colour changes, from green to red, which can be followed by the evolution of $\mathrm{L}^{*}, \mathrm{a}^{*}$ and $\mathrm{b}^{*}$ parameters and the colour indices Chroma and hue angle. The colour index $\left(\mathrm{a}^{*} / \mathrm{b}^{*}\right)$ has been proposed as a good colour index for sweet cherry cultivars (Díaz-Mula et al., 2009), since it shows a continuous increase during fruit ripening on the tree and has been used in other species such as apple, pear and peach. Accumulation of anthocyanins is closely connected with ripening stage of the fruits and is responsible for the red-purple colour of fruits (Serradilla et al., 2011). Maturation of red fruits is followed by the change of the initial green colour to red, violet or blackish colour, caused by accumulation of anthocyanins and by chlorophyll degradation (Serrano et al., 2005). In cherries, colour is mainly influenced by the concentration and distribution of different anthocyanins in the skin (Esti et al., 2002;
Gonçalves et al., 2007). Serrano et al. (2005) found that the decrease in colour parameters were correlated with the greatest accumulation of total anthocyanins. Therefore, it is reasonable to suppose that the colour change observed among different ripening stages of sweet cherries was due to anthocyanin accumulation in the skin. This suggests that colour parameters could be connected to the biological age of the fruits, and in this way, could be especially important in prediction of the optimum harvest date, considering also, the ease of this analytical determination.

Fruit firmness was different for all harvest times, with early-harvest cherries having the highest firmness and lateharvest cherries being the softest (Chauvin et al., 2009). This trend follows the softening of fruit flesh during ripening. According with those found by Serrano et al. (2005), skin firmness decreased with ripening advancement. Kohli et al. (2015) discussed about this mechanism in different fruits attributing this change to increase of $\beta$-galactosidase activity rather than pectin depolymerisation since polygalacturonase activity seems to be negligible during cherry ripening. The same trend observed between hue angle and firmness skin suggests a possible correlation between these parameters that would be useful to estimate one of them measuring the other one.

About fruit removal force and morphological parameters, the changes of diameters and weight were similar to each other for all ripeness stages.

In Table 2, the chemical characteristics of fresh sweet cherries are reported. It can be observed an increase of $\mathrm{pH}$ values and a decrease of titratable acidity (TA) between LI and LII. Total soluble solids (TSS) showed, instead, a progressive increase from LI to LIII. Results of pH, TA and TSS are according with Serrano et al. (2005), Garcia-Montiel et al. (2010) and Milosěvić and Milosěvić (2012). As reported by Halinska and Frenkel (1991), the TSS increase is partially due to the metabolic conversion of acids into sugars by gluconeogenesis, so determining lowering of $\mathrm{TA}$ and consequently the increase of $\mathrm{pH}$ during the ripening process. As well known, this process is not only contributing to the sugar content rising in the fruit but for a considerable part, it is also due to sucrose translocation from plant sources of photosynthesis to the fruits via phloem (Iglesias et al., 2007).

Table 1: Physical and chemical parameters of fresh sweet cherries harvested at three different ripeness stages

\begin{tabular}{|c|c|c|c|c|c|c|c|c|c|}
\hline $\begin{array}{l}\text { Harvest } \\
\text { time }\end{array}$ & $\begin{array}{l}\text { Fruit removal } \\
\text { force }(\mathrm{g})\end{array}$ & Weight (g) & $L^{*}$ & $\begin{array}{c}\text { Hue } \\
\text { angle }\left({ }^{\circ}\right)\end{array}$ & Chroma & $\begin{array}{l}\text { Longitudinal } \\
\text { diameter } \\
(\mathrm{mm})\end{array}$ & $\begin{array}{c}\text { Major } \\
\text { transversal } \\
\text { diameter }(\mathrm{mm})\end{array}$ & $\begin{array}{c}\text { Minor } \\
\text { transversal } \\
\text { diameter }(\mathrm{mm})\end{array}$ & Firmness (N) \\
\hline LI & $255.63 \pm 22.38 a^{*}$ & $5.25 \pm 0.39 b$ & $33.24 \pm 0.50 a$ & $19.87 \pm 0.87 a$ & $25.88 \pm 1.22 a$ & $20.45 \pm 0.65 a$ & $21.92 \pm 0.60 b$ & $19.27 \pm 0.23 c$ & $10.49 \pm 0.01 a$ \\
\hline LII & $229.96 \pm 36.18 a$ & $6.22 \pm 0.08 a$ & $31.46 \pm 0.12 b$ & $16.89 \pm 0.43 b$ & $19.82 \pm 1.15 b$ & $21.27 \pm 0.17 a$ & $23.05 \pm 0.02 a$ & $20.41 \pm 0.10 a$ & $8.82 \pm 0.00 \mathrm{~b}$ \\
\hline LIII & $190.77 \pm 84.57 a$ & $5.95 \pm 0.10 a$ & $30.12 \pm 1.28 b$ & $14.87 \pm 0.46 c$ & $18.70 \pm 0.31 b$ & $20.70 \pm 0.32 a$ & $22.49 \pm 0.30 a b$ & $19.74 \pm 0.29 b$ & $6.76 \pm 0.01 \mathrm{c}$ \\
\hline
\end{tabular}

* The average values that have the equal letters in same column are not significantly different ( $p$-level>0.05) 
Chemical characteristics of smoothies based on sweet cherries are shown in Table 3. A significant difference between ripeness stages was observed for TSS and TA values. In particular, the highest values of TSS was observed in the LIII, whereas a high TA value was obtained in samples made up of sweet cherries harvest at the first ripeness stage. First of all, the increase of TSS in the LIII suggests that thermal treatment carried out by microwaves, even though the high temperature reached during pasteurization processing (the maximum temperature reached inside smoothies during thermal treatment $127^{\circ} \mathrm{C}$ ), did not cause a remarkable degradation of organic acids and soluble sugars by Maillard or caramelization reactions. This was due, probably, to the short treatment time (a few minutes) used. Moreover, the increase of TSS in the LIII could be attributed to the formation of water soluble pectins during fruit aging as reported by Fils-Lycaon and Buret (1990). The differences among TA values of smoothies in the different ripeness stages (that is, subsequent harvest dates) varied accordingly to TA values in sweet cherries at the same stage, but TA in smoothies were quite higher than in fruits (Table 1 and 3). This is in accordance with the hypothesis that the main

Table 2: Chemical characteristics of fresh sweet cherries harvested at three different ripeness stages

\begin{tabular}{lccc}
\hline $\begin{array}{l}\text { Harvest } \\
\text { time }\end{array}$ & pH & $\begin{array}{c}\text { Total soluble } \\
\text { solids }\left({ }^{\circ} \text { Brix) }\right.\end{array}$ & $\begin{array}{c}\text { Titratable acidity } \\
\text { (citric acid g/L) }\end{array}$ \\
\hline LI & $3.73 \pm 0.02 b^{*}$ & $13.33 \pm 0.15 \mathrm{c}$ & $6.89 \pm 0.42 \mathrm{a}$ \\
LII & $3.92 \pm 0.02 \mathrm{a}$ & $15.40 \pm 0.40 \mathrm{~b}$ & $6.16 \pm 0.06 \mathrm{~b}$ \\
LIII & $3.88 \pm 0.07 \mathrm{a}$ & $16.40 \pm 0.26 \mathrm{a}$ & $6.59 \pm 0.45 \mathrm{ab}$ \\
\hline
\end{tabular}

${ }^{*}$ The average values that have the equal letters in same column are not significantly different ( $p$-level $>0.05$ )

Table 3: Chemical characteristics of smoothies made of sweet cherries harvested at three different ripeness stages

\begin{tabular}{lccc|}
$\begin{array}{l}\text { Harvest } \\
\text { time }\end{array}$ & pH & $\begin{array}{c}\text { Total soluble } \\
\text { solids ( }{ }^{\circ} \text { Brix) }\end{array}$ & $\begin{array}{c}\text { Titratable acidity } \\
\text { (citric acid g/L) }\end{array}$ \\
\hline LI & $3.86 \pm 0.13 \mathrm{a}^{*}$ & $12.57 \pm 0.21 \mathrm{~b}$ & $9.05 \pm 0.10 \mathrm{a}$ \\
LII & $3.89 \pm 0.04 \mathrm{a}$ & $12.60 \pm 0.26 \mathrm{~b}$ & $8.19 \pm 0.32 \mathrm{~b}$ \\
LIII & $4.00 \pm 0.03 \mathrm{a}$ & $16.27 \pm 0.21 \mathrm{a}$ & $7.94 \pm 0.19 \mathrm{~b}$ \\
\hline
\end{tabular}

${ }^{*}$ The average values that have the equal letters in same column are not significantly different $(p-l e v e l>0.05)$

Table 4: Sensory vocabulary for analysis of sweet cherries smoothies

\begin{tabular}{lll}
\hline Sensory attributed & Score & \\
\cline { 2 - 3 } & $\mathbf{0}$ & $\mathbf{1 0}$ \\
\hline Colour Intensity & Pink & Dark red \\
Smoothie homogeneity & Heterogeneous & Homogeneous \\
Fruity intensity & Weak & Very intense \\
Herbaceous intensity & Weak & Very intense \\
Off-flavours & None & Very intense \\
Sweetness & Weak & Very intense \\
Sourness & Weak & Very intense \\
Bitterness & Weak & Very intense \\
Overall acceptability & Unpleasant & Pleasant \\
\hline
\end{tabular}

part acid compounds in the fruit have not been affected by heat treatment used and, at the same time, the mechanical effect of the previous homogenization phase could have made available acid groups that were not accessible before.

Fig. 1 reported chromatic characteristics of smoothies made up of sweet cherries harvested at different ripeness stages. Colour changes among the three ripeness stages involved significant differences of $\mathrm{L}^{*}$, hue angle and Chroma. $\mathrm{L}^{*}$ and hue angle decreases followed regularly the ripeness stage while Chroma values decline only from the first to the second ripeness stages. Unlike of $\mathrm{L}^{*}$ values of fresh fruit that decreases from the first to second ripeness stage and remain stable thereafter (Table 1). For the smoothies $\mathrm{L}^{*}$ decreases significantly from the first to the last ripeness stage (Fig. 1A). This could be attributed to the cumulative effects in smoothies of physiological changes occurring during the ripening of cherries (Gonçalves et al., 2007) and the development in a certain measure of Maillard reactions, which is known to induce lowering of $\mathrm{L}^{*}$ (Ganesan and Benjakul, 2014), and is enhanced by the increased sugars content of cherries. Particularly, during ripening of fruits the increase of $\mathrm{pH}$ determine change of anthocyanins colours from red to dark red (Gonçalves et al., 2007) and the presence since the beginning of ripening, when anthocyanins starts to be synthesized and accumulated, of $\mathrm{O}_{2}$ both of endogenous and exogenous origin (related to the natural permeability to gases of the skin tissues). This internal oxygen causes oxidation of anthocyanins and so their change of colour from red to brown, and browning of anthocyanins determine lowering of $\mathrm{L}^{*}$.

Fig. 2 shows results on total polyphenols (TP) in fresh fruits and smoothies of 'Lapins'. It is possible to observe an increase of this parameter between LI and LII for fresh fruits and a significant increase of TP in smoothies as the ripeness proceeds. As could be expected, the changes in chromatic characteristics are in accordance with contents of total polyphenols of 'Lapins' cherries because they are largely represented by anthocyanic compounds that are responsible for red colour of cherries (Figs. 1 and 2). Comparing the polyphenols content of fresh fruits with those of smoothies at the same ripeness stage (Fig. 2), it is possible to observe no significant difference (p-level $>0.05$ ) even if those of smoothies were always slightly lower than those of fresh fruits (466.74 vs $496.51 \mathrm{mg}$ gallic acid per $\left.\mathrm{kg}^{-1}\right)$. This last is in accordance to what could have been expected after a double thermal treatment (blanching and pasteurization by microwaves) applied during processing of cherries (Turturică et al., 2016).

Fig. 3 reported the antioxidant capacity of both sweet cherries fresh fruits and smoothies as a function of ripeness stage. It can be observed that the antioxidant capacity of fresh fruits did not show a significant difference during the 


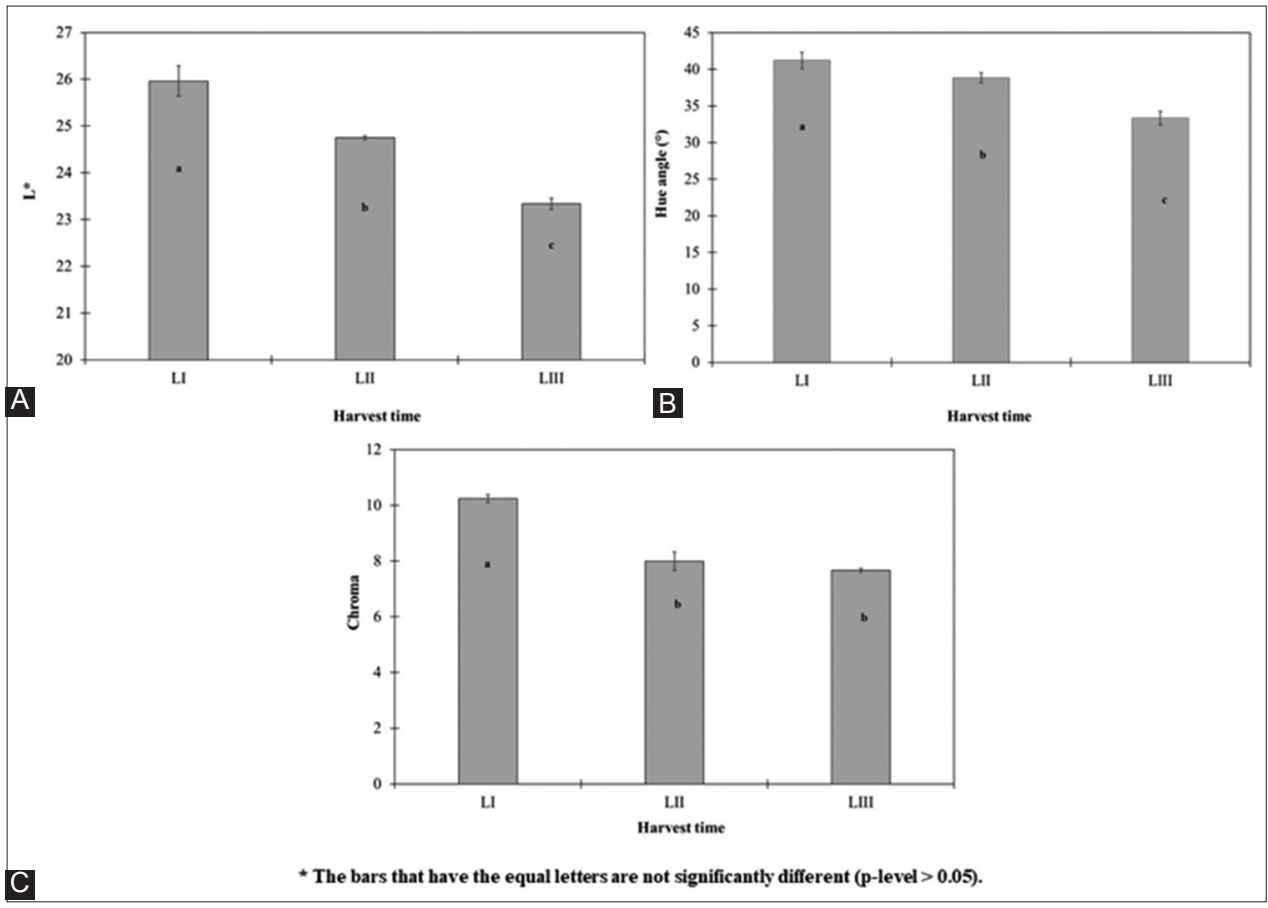

Fig 1. Luminosity $\left(L^{*}\right)(A)$, hue angle $(B)$ and chroma $(C)$ values of smoothies made up of sweet cherries collected at different harvesting dates.

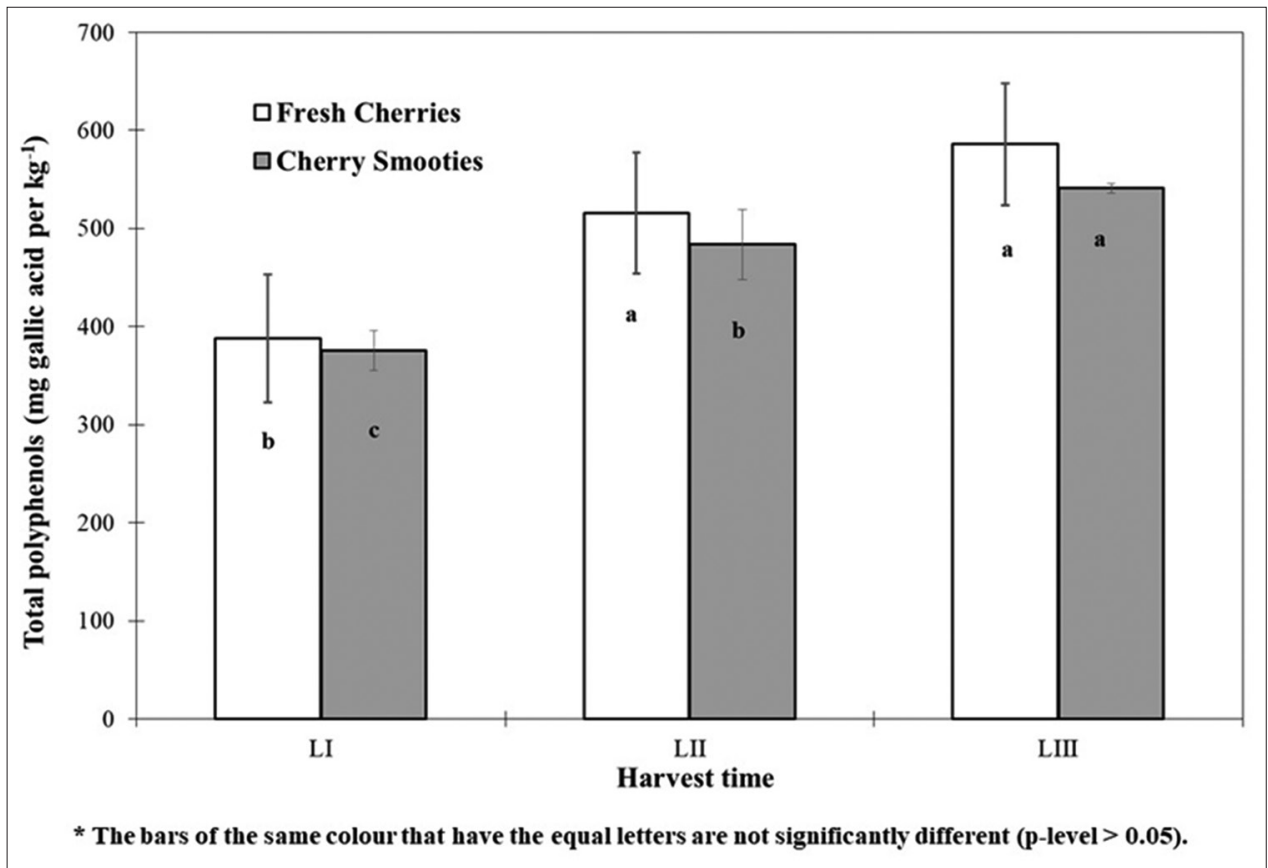

Fig 2. Total polyphenols content of smoothies made up of sweet cherries collected at different harvesting dates.

harvest period ( $\mathrm{p}$-level $>0.05$ ), while this parameter increase significantly in the smoothies ( $\mathrm{p}$-level $<0.05)$. The results of antioxidant capacity of smoothies are in agreement with those of polyphenols content (Figs. 2 and 3). These results are in agreement with those reported by Serrano et al. (2005) who have found a positive correlation in cherry fruits between these two parameters, while Faniadis et al. (2010), which evaluated many cultivars, have found this correlation only in some of those investigated. Considering each single ripeness stage, the antioxidant capacity of smoothies resulted every time significantly lower than in fresh fruits (p-level $<0.05)$. This could be explained with the fact that in fresh fruits there are not only polyphenols as substances with antioxidant capacity but also vitamin $C$ and tocopherols. These last two antioxidant categories are highly thermolabile, so they are degraded when submitted to thermal treatments (Boon et al., 2010; Poiana 


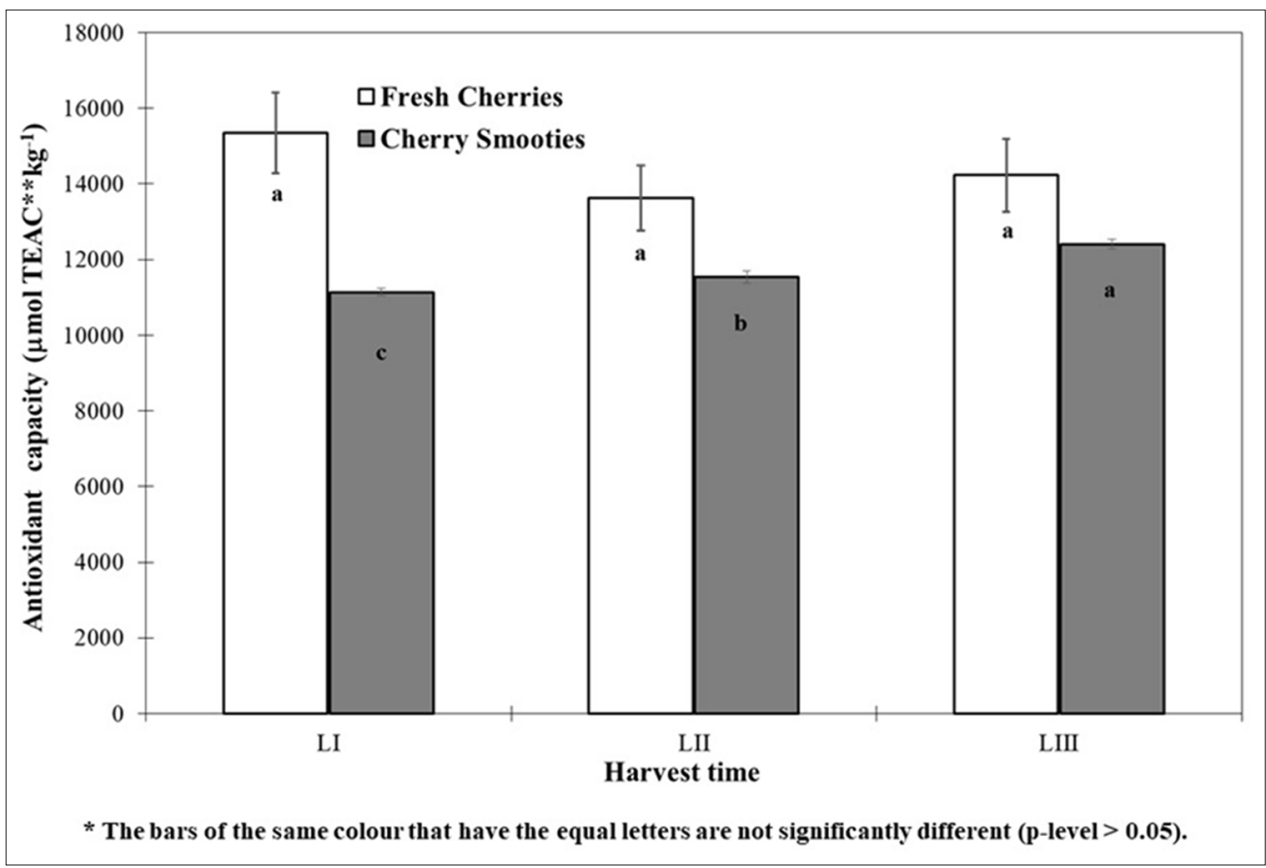

Fig 3. Antioxidant capacity of smoothies made up of sweet cherries collected at different harvesting dates

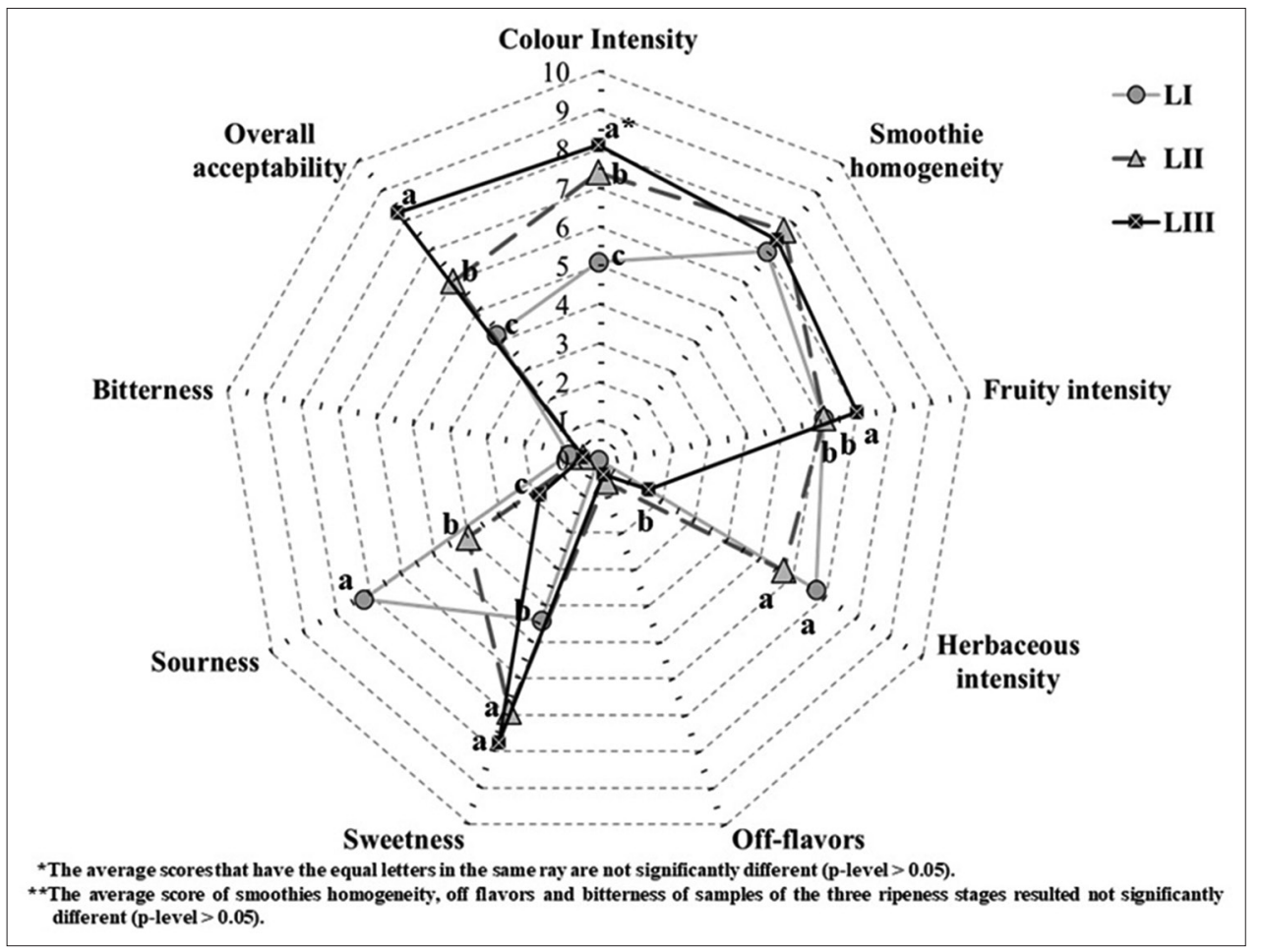

Fig 4. Quality descriptive analysis (QDA) of smoothies made up of sweet collected at different harvesting dates

et al., 2011; Kadian et al., 2013). Then, it is reasonable to suppose that the great part of the residual antioxidant activity is due to polyphenols, which are relatively more resistant to thermal treatments (Turturică et al., 2016; Picariello et al., 2017) and this could explain our results. Nevertheless, the decrease of antioxidant capacity in smoothies respect to fresh fruits was not so relevant respect what could be expected after the double thermal treatment (blanching and pasteurization by microwaves) applied during processing of cherries. The higher speed of the internal heating - compared to that of the traditional methods based on external heat transfer and heat conduction - made microwaves more suitable for these applications. In fact, one of the most significant benefits of microwaves heating is to reduce the negative effects of thermal 
treatment due to its shorter duration (Vadivambal and Jayas, 2007; Camacho et al., 2009).

Fig. 4 shows the sensorial profiles elaborated on the base of a quantitative descriptive analysis (QDA) of smoothies made up of sweet cherries collected at three different harvest times. The increase of ripeness stage involved significant ( $\mathrm{p}$-level < 0.05) increases of colour intensity (scoring from 5.10 to 8.10 ), fruity intensity (scoring from 6.10 to 7.00 ) and sweetness (scoring 4.40 to 7.75 ) and decreases of herbaceous intensity (scoring from 6.70 to 1.55 ) and sourness (scoring from 7.20 to 1.80). These changes improved significantly (p-level <0.05) the sensorial quality of smoothies made up of sweet cherries harvest at the last ripeness stage that obtained the highest score of overall acceptability (8.30). The pasteurization carried out by microwaves did not influence negatively the sensorial characteristics of smoothies because they did not develop any off flavour or noticeable bitterness that could originated by developing of Maillard reactions as consequence of pasteurization treatments. In fact, Lund and Ray (2017) reported that Maillard reactions affect multiple food quality parameters, including sensorial properties, colour, and protein functionality. A specific aroma profile is developed as a function of the temperature-time profiles used during food processing. In some cases like that of processed fruit, the developing of Maillard reactions contribute to undesired quality changes, especially if the Maillard reactions are too pronounced, producing bitter and burnt flavours that are considered as off flavours.

Finally, the sensory analysis showed that the quality of cherry smoothies depend only by characteristics of fresh fruits and that the advancement of ripening, at least within harvest time period for fresh eaten fruits, contribute to improve the acceptability by consumers.

\section{CONCLUSIONS}

Colour indexes measured on fresh cherries resulted quite sensible in determining the stage of ripeness, so validating the worldwide spread use of colour as the most affordable and easy way to estimate the optimal harvest date of cherries.

This research highlights the importance of ripeness stage also for processed fruit. In particular, in our case, the production of smoothies by 'Lapins' sweet cherries should be carried out with fruits of the late harvest period in order to maximise functional and sensorial properties of this product.

\section{ACKNOWLEDGEMENTS}

Special thanks go to Dr. Giuseppe Dalfino, Dr. Ofelia Alessandrino and Dr. Davide Scelsa for the technical contribution given to development of this research.

\section{Authors' Contributions}

All authors contributed substantially to the writing and revising of the manuscript. Lopriore (corresponding author) and De Pilli designed the work, acquired, analysed, and interpreted the data. Lopriore oversaw the experimental phase carried out in the field while De Pilli managed the technological transformation of the fruits. Lopriore and De Pilli critically reviewed, corrected and edited the manuscript.

\section{REFERENCES}

Ames, B. N., M. K. Shigenaga and T. M. Hagen. 1993. Oxidants, antioxidants, and the degenerative disease of aging. Proc. Natl. Acad. Sci. U. S. A. 90: 7915-7922.

Aviram, M. and B. Fuhrman. 2002. Wine flavonoids protect against LDL oxidation and atherosclerosis. Ann. N. Y. Acad. Sci. 957: 146-161.

Boon, C. S., D. J. McClements, J. Weiss and E. A. Decker. 2010. Factors influencing the chemical stability of carotenoids in foods. Crit. Rev. Food Sci. Nutr. 50: 515-532.

Bors, W. and C. A. Michel. 2002. Chemistry of the antioxidant: Effect of polyphenols. Ann. N. Y. Acad. Sci. 957: 57-69.

Cabezas-Serrano, A. B., M. L. Amodio, R. Cornacchia, R. Rinaldi and G. Colelli. 2009a. Suitability of five different potato cultivars (Solanum tuberosum L.) to be processed as fresh-cut products. Postharvest Biol. Technol. 53: 138-144.

Cabezas-Serrano, A. B., M. L. Amodio, R. Cornacchia, R. Rinaldi and G. Colelli. 2009b. Screening quality and browning susceptibility of 5 artichoke cultivars for fresh cut processing. J. Sci. Food Agric. 89: 2588-2594.

Çalhan, O., C. E. Onursal, A. Güneyli, I. Eren and I. Demirtaş. 2014. Determination of optimum harvest date of sweet cherry cv. Lapins grown in Isparta. Turk. J. Agric. Nat. Sci. 2: 1905-1910.

Camacho, M. M., E. Garçía, M. Garçía and N. Martinez. 2009. Microwave pasteurization of grapefruit juice (in Spanish). Aliment. Equipos Tecnol. 244: 34-38.

Cappelletti, G., C. Russo, G. Lopriore, G. Martino, G. M. Nicoletti and D. Scelsa. 2015. Conventional and organic farming methods of sweet cherry (Prunus avium L.): An environmental life cycle analysis approach. Pol. J. Commodity Sci. 4: 70-79.

Chauvin, M. A., M. Whiting and C. F. Ross. 2009. The influence of harvest time on sensory properties and consumer acceptance of sweet cherries. Horttechnology. 19: 748-754.

Daher , D., S. Le Gourrierec and C. Pérez-Lamela. 2017. Effect of high pressure processing on the microbial inactivation in fruit preparations and other vegetable based beverages. Agriculture. 7: 1-18.

Díaz-Mula, H. M., S. Castillo, D. Martínez-Romero, D. Valero and P. J. Zapata. 2009. Sensory, nutritive and functional properties of sweet cherry as affected by cultivar and ripening stage. Food Sci. Technol. Int. 15: 535-543.

Drake, S. R. and D. C. Elfving. 2002. Indicators of maturity and storage quality of 'Lapins' sweet cherry. Horttechnology. 12: 687-690.

Esti, L., F. Cinquanta, E. Sinesio, E. Moneta and M. Di Matteo. 2002. Physicochemical and sensory fruit characteristics of two sweet cherry cultivars after cool storage. Food Chem. 76: 399-405.

Faniadis, D., P. D. Drogoudi and M. Vasilakakis. 2010. Effects of cultivar, orchard elevation, and storage on fruit quality characters of sweet cherry (Prunus avium L.). Sci. Horticult. 125: 301-304.

Emir. J. Food Agric • Vol 30 • Issue 11 • 2018 
Ferretti, G., T. Bacchetti, A. Belleggia and D. Neri. 2010. Review cherry antioxidants: From farm to table. Molecules. 15: 6993-7005.

Fils-Lycaon, B. and M. Buret. 1990. Loss of firmness and changes in pectic fractions during ripening and over ripening of sweet cherry. Hortscience. 25: 777-778.

Ganesan, P. and S. Benjakul. 2014. Effect of glucose treatment on texture and colour of pidan white during storage. J. Food Sci. Technol. 51: 729-735.

Gao, L. and G. Mazza. 1995. Characterization, quantification, and distribution of anthocyanins and colourless phenolics in sweet cherries. J. Agric. Food Chem. 43: 343-346.

Garcia-Montiel, F., M. Serrano, D. Martinez-Romero and N. Alburquerque. 2010. Factors influencing fruit set and quality in different sweet cherry cultivars. Span. J. Agric. Res. 8: 1118-1128.

Gonçalves, B., A. P. Silva, J. Moutinho-Pereira, E. Bacelar, E. Rosa and A. S. Meyer. 2007. Effect of ripeness and postharvest storage on the evolution of colour and anthocyanins in cherries (Prunus avium L.). Food Chem. 103: 976-984.

Halinska, A. and C. Frenkel. 1991. Acetaldehyde stimulation of net gluconeogenic carbon movement from applied malic acid in tomato fruit pericarp tissue. Plant Physiol. 95: 954-960.

Iglesias, D. J., M. Cercós, J. M. Colmenero-Flores, M. A. Naranjo, G. Ríos, E. Carrera, O. Ruiz-Rivero, I. Lliso, R. Morillon, F. R. Tadeo and M. Talon. 2007. Physiology of citrus fruiting. Braz. J. Plant Physiol. 19: 333-362.

Kadian, S. S., A. Sharma and D. R. Sood. 2013. Effect of light and heat on stability of crude carotenoid extract from natural sources. Int. J. Pharm. Sci. Res. 4: 2415-2418.

Keenan , D. F., N. Brunton, R. Gormley and F. Butler. 2011. Effects of thermal and high hydrostatic pressure processing and storage content of polyphenol and some quality attributes of fruit smoothies. J. Agric. Food Chem. 59: 601-607.

Kohli, P., M. Kalia, and R. Gupta. 2015. Pectin methylesterases: A review. J. Bioprocess Biotech. 5: 1-7.

Lonza, L. 2013. Ai consumatori piace brik. Beverage Grocery. 62: 34-35.

Lund, M. N. and C. A. Ray. 2017. Control of maillard reactions in foods: Strategies and chemical mechanisms. J. Agric. Food Chem. 65: 4537-4552.

McGuire, R. G. 1992. Reporting of objective colour measurements. Horttechnology. 27: 1254-1255.

Meilgaard, M. C., B. T. Carr and G. V. Civillem. 1999. Sensory Evaluation Techniques. $3^{\text {rd }}$ ed. CRC Press, Boca Raton, FL.

Melichácová, S., M. Timoracká, J. Bystrická, A. Vollmannová and J. Céry. 2010. Relation of total antiradical activity and total polyphenol content of sweet cherries (Prunus avium L.) and tart cherries (Prunus cerasus L.). Acta Agric. Slov. 95: 21-28.

Milosěvić, T. and N. Milosěvić. 2012. Fruit quality attributes of sour cherry cultivars. Int. Sch. Res. Netw. Agron. 2012: 1-5.

Mordor Intelligence Analysts. 2017. North America Smoothies Market. Report 2017-2022. pp. 1.

Oz, A. T. and E. Kafkas. 2017. In: S. Naofumi (Ed.), Phytochemicals in Fruits and Vegetables, Superfood and Functional Food-an Overview of their Processing and Utilization. InTech. DOI: 10.5772/66987. Available from: https://www.intechopen.com/books/superfood-andfunctional-food-an-overview-of-their-processing-and-utilization/ phytochemicals-in-fruits-and-vegetables.

Picariello, G., P. Ferranti, F. De Cunzo, E. Sacco and M. G. Volpe.
2017. Polyphenol patterns to trace sweet (Prunus avium L.) and tart (Prunus cerasus L.) varieties in cherry jam. J. Food Sci. Technol. 54: 2316-2323.

Piccolella , S., A. Fiorentino, S. Pacifico, B. D'Abrosca, P. Uzzo and P. Monaco. 2008. Antioxidant properties of sour cherries (Prunus cerasus L.): Role of colourless phytochemicals from the methanolic extract or ripe fruits. J. Agric. Food Chem. 56: 1928-1935.

Poiana, M. A., D. Moigradean, D. Dogaru, C. Mateescu, D. Raba and I. Gergen. 2011. Processing and storage impact on the antioxidant properties and color quality of some low sugar fruit jams. Rom. Biotech. Lett. 16: 6504-6512.

Santana, P., N. Huda and T. A. Yang. 2015. Physicochemical properties and sensory characteristics of sausage formulated with surimi powder. J. Food Sci. Technol. 52: 1507-1515

Schumacher, H. R., S. Pullman-Mooar, S. R. Gupta, J. E. Dinnella, R. Kim and M. P. McHugh. 2013. Randomized double-blind crossover study of the efficacy of a tart cherry juice blend in treatment of osteoarthritis (OA) of the knee. Osteoarthritis Cartilage. 21: 1035-1041.

Seeram, N. P., R. A. Momin, M. G. Nair and L. D. Bourquin. 2002. Cyclooxygenase inhibitory and antioxidant cyanidin glycosides in cherries and berries. Phytomedicine. 8: 362-369.

Serradilla, M. J., M. Lozano, M. J. Bernalte, M. C. Ayuso, M. LópezCorrales and D. González-Gómez. 2011. Physicochemical and bioactive properties evolution during ripening of 'Ambrunés' sweet cherry cultivar. LWT Food Sci. Technol. 44: 199-205.

Serrano, M., F. Guillén, D. Martínez-Romero, S. Castillo and D. Valero. 2005. Chemical constituents and antioxidant activity of sweet cherry at different ripening stages. J. Agric. Food Chem. 53: 2741-2745.

Singleton, V. L. and J. A. Rossi. 1965. Colourimetry of total phenolics with phosphomolybdic-phosphotungstic acid reagents. Am. J. Enol. Vitic. 16: 144-158.

Turturică, M., N. Stănciuc, G. Bahrim and G. Râpeanu. 2016. Investigations on sweet cherry phenolic degradation during thermal treatment based on fluorescence spectroscopy and inactivation kinetics. Food Bioprocess Technol. 9: 1706-1715.

Vadivambal, R. and D. S. Jayas. 2007. Changes in quality of microwavetreated agricultural products-a review. Biosyst. Eng. 98: 1-16.

Viljevac, M., K. Dugalić, V. Jurković, I. Mihaljević, V. Tomaš, B. Puškar, H. Lepeduš, R. Sudar and Z. Jurković. 2012. Relation between polyphenols content and skin colour in sour cherry fruits. J. Agric. Sci. 57: 57-67.

Walking , R. M., F. Noci, D. A. Cronin, J. G. Lyng and D. J. Morgan. 2010. Shelf life and sensory attributes of a fruit smoothie-type beverage processed with moderate heat and pulsed electric fields. LWT Food Sci. Technol. 43: 1067-1073.

Wang, H., M. G. Nair, A. F. lezzoni, G. M. Strasburg, A. M. Booren and J. I. Gray. 1997. Quantification and characterization of anthocyanins in Balaton tart cherries. J. Agric. Food Chem. 45: 2256-2260.

Wang, H., M. G. Nair, G. M. Strasburg, A. M. Booren and J. I. Gray. 1999a. Antioxidant polyphenols from tart cherries (Prunus cerasus L.). J. Agric. Food Chem. 47: 840-844.

Wang, H., M. G. Nair, G. M. Strasburg, Y. C. Chang, A. M. Booren, J. I. Gray and D. L. DeWitt. 1999b. Antioxidantand antiinflammatory activities of anthocyanins and their aglycon, cyanidin, from tart cherries. J. Nat. Prod. 62: 294-296. 